\title{
Assessment of reproductive function in southern African spiny mice (Acomys spinosissimus) using faeces as hormone matrix
}

\author{
P. Ruan de Bruin ${ }^{1 *}$, Katarina Medger', Nigel C. Bennett ${ }^{1}$ \& André Ganswindt ${ }^{1,2^{\ddagger}}$ \\ ${ }^{1}$ Mammal Research Institute, Department of Zoology and Entomology, University of Pretoria, \\ Pretoria, 0002 South Africa \\ ${ }^{2}$ Department of Production Animal Studies, Faculty of Veterinary Science, University of Pretoria, \\ Onderstepoort, 0110 South Africa \\ Received 9 September 2013. Accepted 12 November 2013
}

\begin{abstract}
For spiny mice, detailed long-term data on reproductive endocrine function is lacking, as limited blood volumes make frequent collections of individual plasma samples for hormone monitoring impractical. To provide the necessary tools in order to fill this gap, this study examined the suitability of two enzyme immunoassays for monitoring male and female reproductive function in the southern African spiny mouse (Acomys spinosissimus) based on faecal hormone analysis. Fourteen non-pregnant and one pregnant female and 24 male spiny mice were wild-caught and subsequently monitored under controlled conditions. Thirteen of the 14 non-pregnant females revealed elevated faecal progestagen metabolite concentrations with eight individuals showing indications of a luteal phase. Two females showed two post-ovulatory luteal phases with estimated cycle lengths of 16 and 18 days, respectively. The pregnant female had an elevated (231\%) mean faecal progestagen metabolite level compared with the overall mean baseline hormone concentration determined for the 14 non-pregnant females. Males exposed to a long photoperiod, simulating summer-related breeding activity, exhibited a $47.8 \%$ increase in faecal androgen metabolite levels compared with males exposed to a short photoperiod. Collectively, the data demonstrated that reproductive endocrine function can be monitored in male and female spiny mice by measuring respective faecal hormone metabolites.
\end{abstract}

Key words: Acomys spinosissimus, southern African spiny mouse, progestagens, androgens, non-invasive hormone monitoring.

\section{INTRODUCTION}

The genus Acomys has become an important group of rodents for behavioural and physiological studies as they are found across a wide range of habitats ranging from rocky country to semi-desert areas, dry woodlands and savannas (Bates 1994; Nowak 1999; Shargal et al. 2000; Nováková et al. 2008). Spiny mice are especially well adapted to areas with very limited water supply such as deserts, raising the questions on how they survive in these harsh environments (Shanas \& Haim 2004; Wube et al. 2008). In this regard, information about species-specific reproductive processes would be useful, but even basic reproductive knowledge, especially in terms of endocrine correlates of reproductive function, is still limited for the entire genus, with the common spiny mouse (Acomys cahirinus) and golden spiny mouse (Acomys russatus) being the only two of 14 Acomys species

*Author for correspondence. E-mail: prdebruin@zoology.up.ac.za

*Present address: Department of Anatomy and Physiology, Faculty of Veterinary Science, University of Pretoria, Onderstepoort, 0110 South Africa. for which reproductive endocrinology has been investigated (Peitz 1981; Bates 1994; van Aarde \& Haim 1999). For these two species an oestrous cycle length of about 11-18 days has been found, which is considered comparatively long for a rodent of such small size. The average oestrous cycle length of most mice species is defined between five and seven days (Parkes 1926; Peitz 1981; van Aarde \& Haim 1999), and for gerbils, which are closely related to Acomys, an oestrous cycle of four to six days has been described (Nishino \& Totsukawa 1996).

The southern African spiny mouse (Acomys spinosissimus) is confined to the rocky areas of the northeastern parts of South Africa and can be found as far north as Mozambique, Zimbabwe and Tanzania (Verheyen et al. 2011). Verheyen et al. (2011) have recently concluded that the species found in South Africa might be a distinct species known as Acomys selousi, but for the purpose of this paper we will continue referring to the species as Acomys spinosissimus. Gonadal cross-section 
data from Medger and colleagues (2010, 2012a) showed that the onset of the breeding season of Acomys spinosissimus coincides with the respective summer rainy seasons in the area. Females were found to be pregnant only from September until January with accompanying higher plasma progesterone levels and greater follicular development during this time of the year (Medger et al. 2010). When exposed to a long photoperiod, simulating summer, spiny mice males had greater testicular mass and volume, as well as elevated plasma testosterone concentrations compared to males subjected to a simulated winter situation (Medger et al. 2012b).

Currently, no long-term data on reproductive endocrine function exists for Acomys spinosissimus, or any other Acomys species, as limited blood volumes make it impossible to frequently collect plasma on an individual basis (K. Medger, pers. obs.). However, repeated sampling for hormone analysis is often mandatory in order to accurately predict and monitor reproductive processes such as seasonality, ovulation, cycle length, or pregnancy (Schwarzenberger et al. 1996; Hodges et al. 2010). As frequent collection of blood for hormone analysis has proven challenging especially in free-ranging non-domesticated animals, as well as comparatively small species like many rodents including Acomys, alternative sampling methods have often been developed for species where repeated blood collection is not feasible (Cavigelli et al. 2005; Valades et al. 2012). One well-established approach to monitor reproductive endocrine function in small, non-domesticated animals is through the use of faeces as a hormone matrix, as faeces can be non-invasively collected and therefore animals are usually not disturbed during sample collection (Schwarzenberger 2007; Frynta et al. 2009). Faeces have therefore been used in order to characterize reproductive activity in terms of determining oestrous cycle length, pinpointing ovulation, or monitoring pregnancy as well as seasonal patterns of reproduction in a variety of rodents (Kuznetsov et al. 2004; Busso et al. 2005; Cavigelli et al. 2005; Busso et al. 2007). However, in case of Acomys, faeces have so far only been used to monitor the effect of various intrinsic and extrinsic factors on glucocorticoid metabolite output in common spiny mice (Frynta et al. 2009).

The sex steroids, androgens and progestagens, are primarily secreted by the testes and corpus luteum, respectively, and metabolized in the liver before being excreted via urine or faeces; in the latter case typically in an unconjugated form (Touma \& Palme 2005; Schwarzenberger 2007). Due to the species-specific differences in hormone metabolite excretion (Palme et al. 1996; Busso et al. 2005) and the presence of different steroid metabolites in the excreta of even closely related species (e.g. Berkeley et al. 1997; Schwarzenberger et al. 2000; Brown et al. 2001), respective assays should be validated in terms of their applicability for the hormone matrix of interest to ensure a reliable quantification of respective hormone metabolites (Hodges et al. 2010).

The overall aim of this study was to examine the suitability of two enzyme immunoassays (EIAs), detecting faecal androgen and progestagen metabolites, respectively, for monitoring reproductive function in Acomys spinosissimus. More specifically, the aims of this study were four-fold: 1) defining the minimum sample mass required in order to accurately determine hormone metabolite concentrations in spiny mice faeces; 2) investigating the effect of storage by determining the rate of metabolism of faecal androgens and progestagens post-defecation; 3) monitoring luteal activity and defining ovarian cyclicity, and 4) comparing faecal androgen metabolite levels in reproductively active and inactive males.

\section{METHODS}

\section{Study animals}

During May and July 2011, 14 non-pregnant female $(17.10 \pm 2.52 \mathrm{~g}$; mean \pm S.D) and 24 male spiny mice (19.33 $\pm 3.76 \mathrm{~g})$ were trapped at the Goro Game Reserve $\left(22^{\circ} 58^{\prime} \mathrm{S}, 22^{\circ} 57^{\prime} \mathrm{S}, 29^{\circ} 25^{\prime} \mathrm{E}\right.$, $29^{\circ} 24^{\prime} \mathrm{E}$ ) in the Limpopo Province, South Africa, while a single pregnant female was additionally captured in September 2012 in the same area. Sherman live traps (H.B. Sherman Traps, Inc. Tallahassee, Florida, U.S.A.) were baited with a peanut butter, oats and fish mixture before being set out in the late afternoon for a total of 20 days. The traps were left overnight and collected before sunrise the next morning to ensure that the animals did not undergo any unnecessary stress due to over-heating or starvation. The animals were subsequently sexed and kept in individual cages prepared with wood shavings and paper towel as bedding and cover, respectively. The mice were fed a combination of standard mouse pellets, carrots, apples and bird seeds, and water was available ad libitum. Within seven days, all animals were transported to the small mammal research facility at the University of Pretoria. The study was 
conducted with permission of the Animal Use and Care Committee (EC008-11) of the University of Pretoria, South Africa.

\section{Experimental design}

In the laboratory, the 14 female spiny mice were kept in individual cages under controlled conditions at $25^{\circ} \mathrm{C}$ and on a light cycle of 14 hours light and 10 hours dark (14L:10D) for six weeks to ensure that no individuals were pregnant during the time of capture. At the beginning of September 2011, the females were placed in olfactory, visual, and partly physical contact with vasectomized males to potentially stimulate ovarian endocrine activity. For 35 days, individual faecal matter was collected every other day from all females by temporarily placing the animals in respective collection chambers (UNO, Zevenaar, Holland) for nine hours. The chambers were checked for faeces every three hours and the respective material was combined for each female. Afterwards all animals were returned to their cages. All sampled material was frozen at $-20^{\circ} \mathrm{C}$ immediately after collection and stored until analysis.

A single pregnant female spiny mouse was housed under the same laboratory conditions, but without male contact and the respective faecal material was collected and stored as mentioned above. Six samples were obtained over 12 days before parturition after which sample collection was halted to avoid unnecessary stress to the mother and young, therefore no post-pregnancy samples could be obtained.

The 24 male spiny mice were initially housed as described above. From beginning of December 2011 onwards, 12 males were subjected to a short photoperiod cycle (10L:14D), while the remaining 12 males were continuously kept on a $14 \mathrm{~L}: 10 \mathrm{D}$ light cycle, representing a long photoperiod cycle. The different light cycles simulate the breeding and non-breeding season of Acomys spinosissimus, respectively, as defined by Medger et al. (2012b). The following six weeks, individual faecal samples were collected every other day, by cleaning the individual cages in the morning and subsequently collecting freshly produced faeces every two hours for six hours in total. The material were collected and stored as mentioned above until further processing.

\section{Effects of storage}

The stability of hormone metabolites post-defecation was investigated by following the proce- dure described by Laver et al. (2012). Fresh faecal matter from one female spiny mouse was additionally collected over a period of 12 days, homogenized, and divided into 12 subsamples, which were stored at room temperature. Subsequently, three subsamples were frozen at $-20^{\circ} \mathrm{C}$ after $0,1,2$, and 3 hours post-defecation, respectively.

\section{Sample processing and extraction}

To reveal information regarding the minimal appropriate mass for hormone measurement (Millspaugh \& Washburn 2004), fresh faecal matter from six male spiny mice was additionally collected prior to the main experiments, homogenized and divided five times into equal subsamples of $10,20,30,40,50$, and $75 \mathrm{mg}$. The resulting 30 samples were extracted as described below and respective extracts subsequently measured for immuno-reactive glucocorticoid metabolites using an 11-oxoetiocholanolone enzyme immunoassay (Möstl et al. 2002), which has been shown to reliably reflect adrenocortical function in spiny mice (Frynta et al. 2009).

The frozen faecal samples were lyophilized and the resulting dried faecal matter pulverized. Between $25-50 \mathrm{mg}$ of the dry faeces was then extracted with $1 \mathrm{ml}$ of $80 \%$ ethanol in water by vortexing for $15 \mathrm{~min}$. Following centrifugation for 2 min at $1500 \mathrm{~g}$, supernatants were transferred into micro-centrifuge tubes and stored at $-20^{\circ} \mathrm{C}$ until hormone analysis.

\section{Hormone analysis}

Resulting extracts were measured for immunoreactive faecal androgen metabolites (FAM) and faecal progestagen metabolites (FPM) using enzyme immunoassays for epiandrosterone (Palme \& Möstl 1993) and 5ß-pregnane-3a-ol-20-one (Schwarzenberger et al. 1996), respectively. Sensitivities (90\% binding) of the assays were of $3 \mathrm{pg} /$ well for both assays. Serial dilutions of extracted faecal samples gave displacement curves that were parallel to the respective standard curves in both assays. Intra- and inter-assay coefficients of variation, determined by repeated measurements of high- and low-value quality controls ranged between $8.6 \%$ and $14.7 \%$ for FAM, and $8.6 \%$ and $17.3 \%$ for FPM measurements. Assays were performed on microtitre plates as described by Ganswindt et al. (2002).

\section{Data analysis}

To determine the minimal appropriate faecal mass for hormone analyses, we tested for differ- 
ences in the distribution of hormone metabolite concentrations among sample subsets using Friedman's rank sum test (whereby each subset consists of the above-mentioned five subsamples with equal faecal mass for hormone extraction). Furthermore, the variability in hormone metabolite levels within each subset was determined by calculating the respective coefficient of variations. Differences in relative degradation rate between samples stored at $t=0 \mathrm{~h}$ and of faeces stored at 1,2, and $3 \mathrm{~h}$ post-defecation, respectively, were examined using one-way repeated measures analysis of variance, followed by a post hoc analysis making use of Bonferroni $t$-test, with the application of Bonferroni correction. The method described in Brown et al. (1999) was followed to deduce individual baseline FPM values. For that, all FPM concentrations of an individual data set exceeding the mean +1.5 standard deviations (S.D.) were excluded, the average successively recalculated, and the elimination process repeated until no values exceeded the mean + 1.5 S.D. The remaining values yielded the baseline FPM concentrations. More than one consecutive FPM value above the baseline concentration was taken as the onset of a luteal phase of an oestrous cycle and thus of ovulation and the post-ovulatory formation of a corpus luteum (van Aarde \& Haim 1999). Oestrous cycle lengths were calculated as the interval in days between the onsets of two luteal phases resulting in cycle lengths only being recorded for females that experienced at least two post-ovulatory luteal phases. Revealed FPM concentrations from the monitored pregnant female were averaged and compared to the overall mean FPM baseline concentration revealed for the other 14 monitored

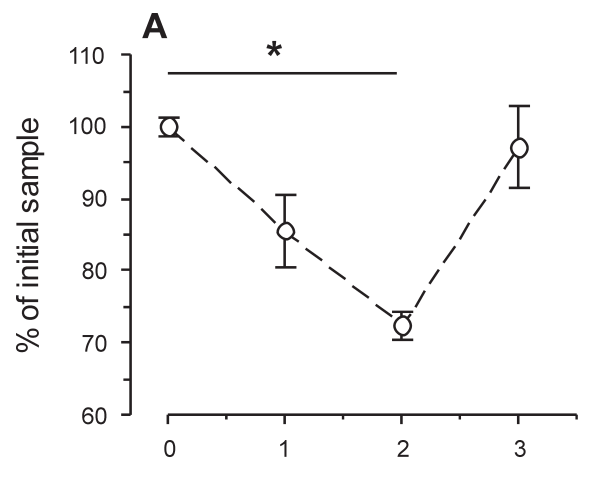

Hours since defecation females. Differences in median FAM levels from males kept either under short or long day conditions were examined using a $t$-test. All tests were two tailed, with the $\alpha$ level of significance set at 0.05 . The programs Jandel Sigma Stat, version 2.0 and KyPlot, version 2.0 beta 13, were used for statistical analyses.

\section{RESULTS}

\section{Effects of storage}

Spiny mice mean FPM levels decreased by $14.6 \%$ and $27.7 \%$ in samples frozen 1 and $2 \mathrm{~h}$ postdefecation, respectively, before reaching $97.1 \%$ of the original hormone concentration after $3 \mathrm{~h}$ post-defecation (Fig. 1A). A statistically significant difference was found between $0 \mathrm{~h}$ and $2 \mathrm{~h}$ postdefecation samples $\left(F_{3}=8.42, P=0.014\right.$; post hoc analysis: $P=0.012$ ).

The revealed pattern of spiny mice FAM concentrations post-defecation was quite similar to the determined FPM levels, but with an overall higher variability in FAM levels even for the sample triplet stored at $t=0$ (Fig. 1B). Mean FAM levels decreased by $7.0 \%$ and $22.4 \%$ in samples frozen 1 and $2 \mathrm{~h}$ post-defecation, respectively, and subsequently reached an averaged $84.5 \%$ of the original concentration after $3 \mathrm{~h}$ post-defecation (Fig. 1B). No statistically significant difference was found between the samples stored at $t=0 \mathrm{~h}$ and of faeces stored at 1,2 , and $3 \mathrm{~h}$ post-defecation $\left(F_{3}=1.49, P=0.31\right)$.

\section{Sample processing and extraction}

No significant changes in spiny mice faecal glucocorticoid metabolite (FGM) concentrations were found between the six analysed sample sub-

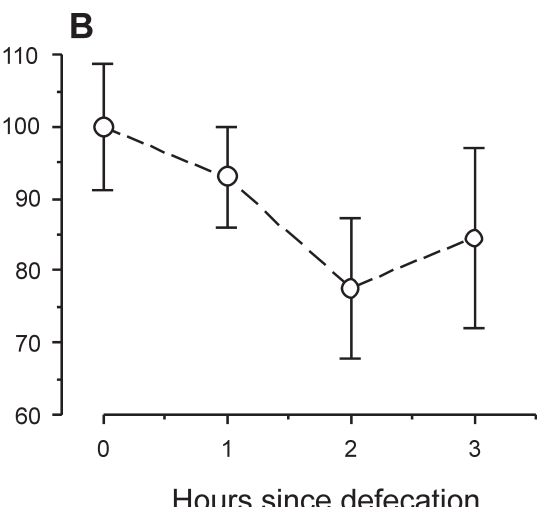

Hours since defecation

Fig. 1. Relative changes (\%) of faecal progestagen metabolite (A) and faecal androgen metabolite levels (B) (mean \pm SEM) in spiny mouse (Acomys spinosissimus) faeces over time (0, 1, 2 and 3 hours since defecation). *Indicates significant difference between samples. 


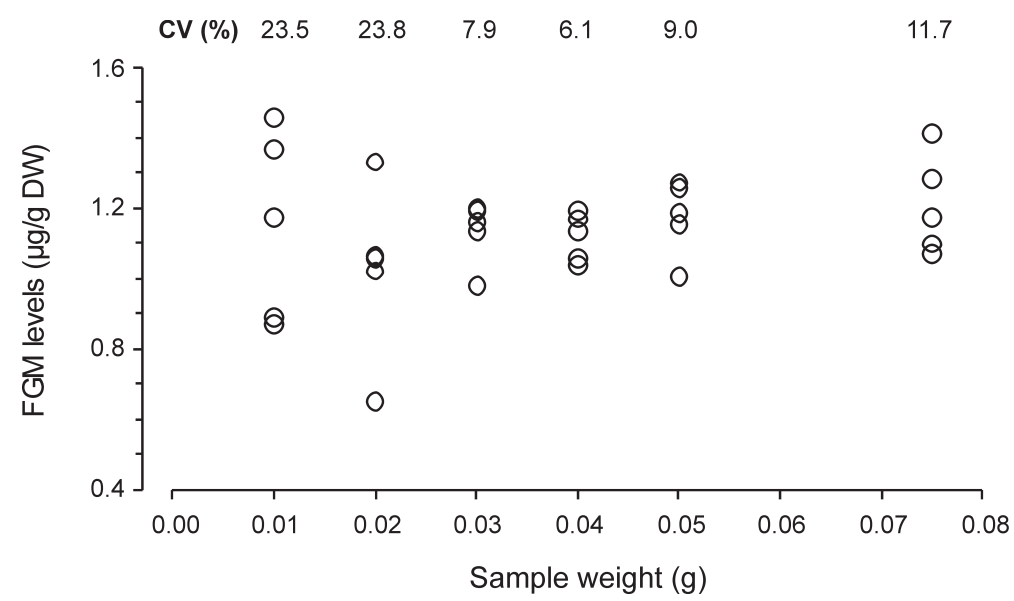

Fig. 2. Faecal glucocorticoid metabolite (FGM) levels from the six sample subsets representing the different faecal mass from spiny mice (Acomys spinosissimus) (10, 20,30, 40, 50, and $75 \mathrm{mg}$, respectively) used for hormone analysis. The coefficient of variation (CV) for each sample subset $(n=5)$ is given at the top.

sets $\chi^{2}=3.60$, d.f. $=5, P=0.61$; Fig. 2). FGM levels varied within each subset, with the highest coefficient of variations found for sample subsets with relatively little faecal matter (Fig. 2). Subsequently, only samples with an available minimum amount of $25 \mathrm{mg}$ dry faecal matter were further processed for the remaining experiments, excluding 359 out of 787 collected samples.

\section{Female reproductive activity}

Thirteen out of the 14 monitored spiny mice females had elevated FPM concentrations with eight out of 14 individuals showing indications of a luteal phase (Table 1). Two females (A35 and A97) showed two post-ovulatory luteal phases with estimated cycle length of 16 and 18 days, respectively (Fig. 3).

The verified pregnant female had elevated mean FPM levels of $231 \%$ (mean \pm S.D.: $2.39 \pm 0.91 \mu \mathrm{g} / \mathrm{g}$ dry weight; $n=6$ ) compared to the overall mean baseline FPM concentration $(0.72 \mu \mathrm{g} / \mathrm{g}$ dry weight $)$ revealed for the 14 non-pregnant females.

\section{Male reproductive activity}

For 23 of the 24 monitored spiny mice males $2-5$ samples with a total mass $\geq 25 \mathrm{mg}$ dry faecal

Table 1. Individual baseline and elevated faecal progestagen metabolite (FPM) concentrations (mean \pm S.D) of 14 captive spiny mice females monitored for 35 days.

\begin{tabular}{llcc}
\hline \multirow{2}{*}{ Female code } & \multicolumn{1}{c}{ FPM levels $(\mu \mathrm{g} / \mathrm{g} \mathrm{DW})$} & Indications of luteal phase \\
\cline { 2 - 4 } & Baseline (mean \pm S.D.) & Elevated (mean \pm S.D.) & No \\
\hline A1 & $0.88 \pm 0.16(n=11)$ & $1.69 \pm 0.39(n=2)$ & Yes \\
A5 & $0.77 \pm 0.14(n=10)$ & $1.32 \pm 0.34(n=4)$ & Yes \\
A7 & $0.78 \pm 0.20(n=8)$ & $1.49 \pm 0.31(n=4)$ & No \\
A9 & $0.80 \pm 0.18(n=7)$ & $1.49(n=1)$ & Yes \\
A10 & $0.53 \pm 0.06(n=7)$ & $1.26 \pm 0.60(n=4)$ & Yes \\
A21 & $0.66 \pm 0.15(n=9)$ & $1.08 \pm 0.10(n=5)$ & Yes \\
A35 & $0.41 \pm 0.06(n=8)$ & $0.96 \pm 0.45(n=7)$ & Yes \\
A36 & $0.84 \pm 0.22(n=9)$ & $1.96 \pm 0.50(n=3)$ & No \\
A41 & $0.80 \pm 0.10(n=6)$ & - & No \\
A49 & $0.65 \pm 0.08(n=12)$ & $1.02 \pm 0.07(n=3)$ & Yes \\
A90 & $0.85 \pm 0.26(n=10)$ & $1.40(n=1)$ & Yes \\
A97 & $0.62 \pm 0.09(n=7)$ & $1.27 \pm 0.38(n=7)$ & No \\
A108 & $0.59 \pm 0.08(n=7)$ & $1.02 \pm 0.26(n=3)$ & $1.15 \pm 0.07(n=2)$ \\
A110 & $0.93 \pm 0.09(n=11)$ & & \\
\hline
\end{tabular}

${ }^{\S}$ Females with two identified post-ovulatory luteal phases. 


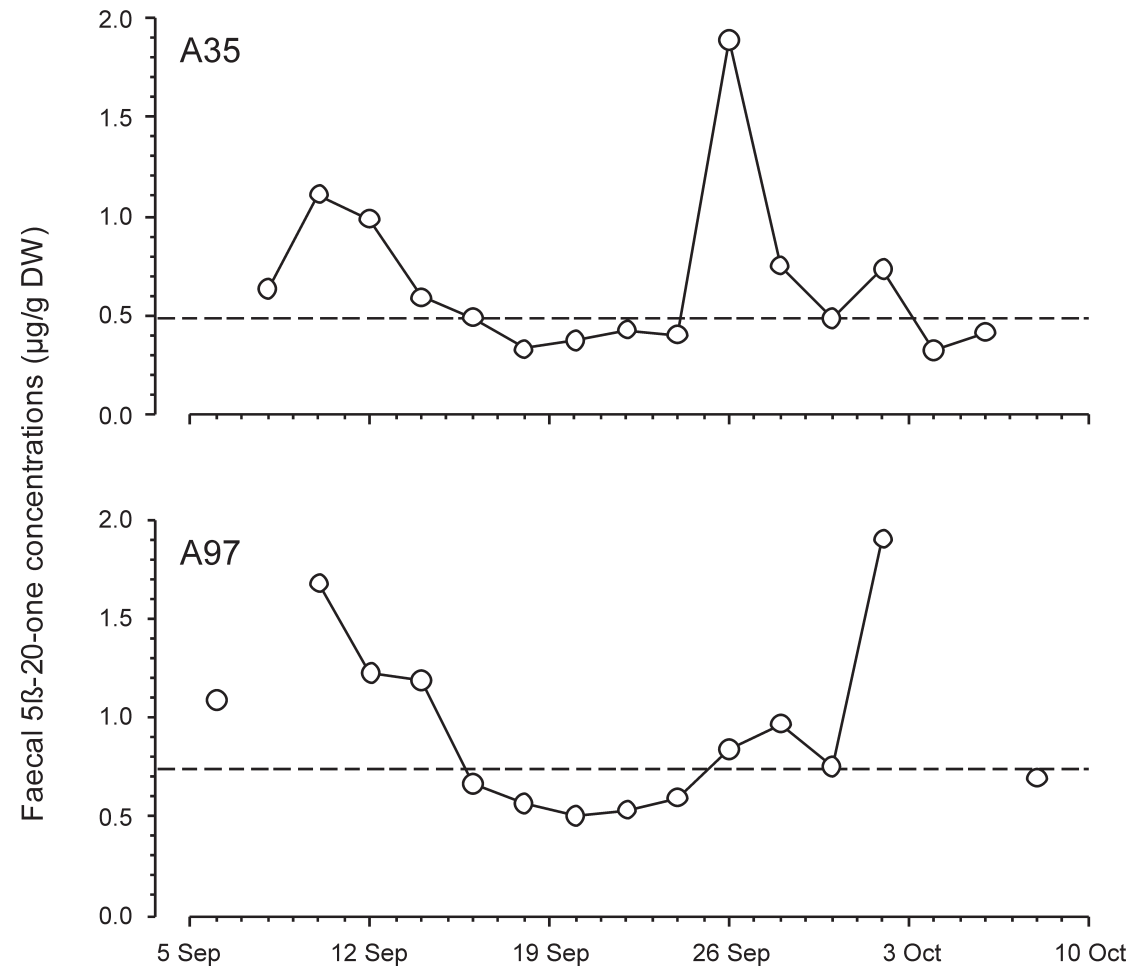

Fig. 3. Profiles of faecal progestagen metabolite (FPM) immunoreactivity throughout a period of 35 days in two female spiny mice (Acomys spinosissimus). Dotted line indicates the individual threshold values for FPM.

matter were obtained. There was a statistically significant difference between FAM levels of males exposed to a short photoperiod when compared to the FAM concentrations of males exposed to a long photoperiod $(t=-2.27, P=0.034)$ with long-day males having on average $47.8 \%$ higher FAM values (Fig. 4).

\section{DISCUSSION}

With this study we have shown that changes in faecal androgen and progestagen metabolite concentrations can be reliably monitored in the spiny mouse using enzyme immunoassays for epiandrosterone and $5 \beta$-pregnane-3a-ol-20-one, respectively. We therefore examined the accompanying sample collection and hormone extraction procedure by investigating the effect of storage on the rate of hormone metabolism post-defecation and defined the minimum sample mass required for hormone extraction. We further examined the reliability of the two assays mentioned. This was done by identifying luteal activity via respective changes in faecal progestagen metabolite (FPM) levels of female spiny mice, as well as by comparing faecal androgen metabolite (FAM)

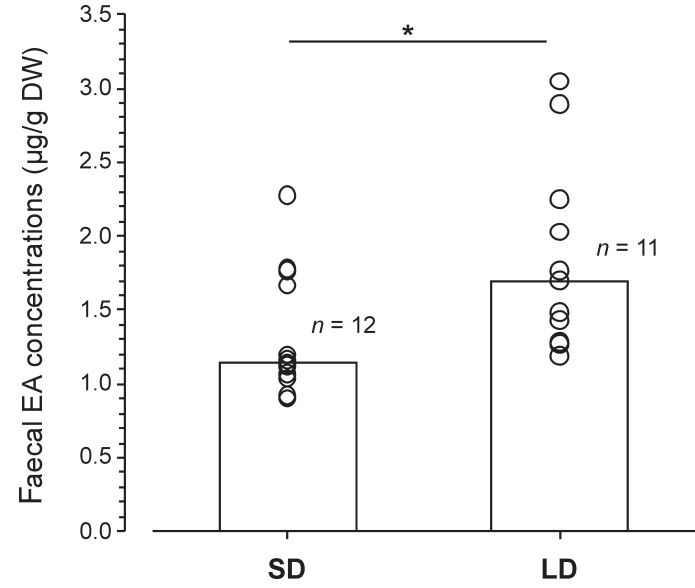

Fig. 4. Individual mean faecal androgen metabolite (FAM) concentrations for spiny mice (Acomys spinosissimus) males exposed to a short (SD) or a long photoperiod (LD) over the six-week experimental period. *Indicates significant difference between samples.

levels of reproductively active and inactive males.

Modification by bacteria has been considered responsible for alterations in steroid metabolite levels in unpreserved faecal samples (Goymann 2012), as microbial activity could alter hormone 
metabolite composition in the matrix, which might then be reflected in respective changes of hormone metabolite concentrations detected, depending on the specificity of the antibody used (Millspaugh \& Washburn 2004; Lexen et al. 2008). In this regard, freezing faecal samples directly after defecation seems to be a reliable way of slowing down or even preventing microbial activity and the breakdown of steroid hormone metabolites post-defecation (Pettitt et al. 2007). In our study, mean FPM and FAM levels decreased by $27.7 \%$ and $22.4 \%$, respectively, after storing freshly produced spiny mouse faeces for $2 \mathrm{~h}$ unpreserved at ambient temperature. This trend is in line with findings from other studies determining changes in faecal glucocorticoid metabolite concentrations post-defecation (e.g. Laver et al. 2012; Ludwig et al. 2013), and even a conversion of the bacterial milieu could eventually be considered as a possible explanation for the decrease in hormone levels found (Lexen et al. 2008). Interestingly, in spiny mice, FPM and FAM concentrations started to increase afterwards, reaching $97.1 \%$ and $84.5 \%$ of the initial hormone concentration after $3 \mathrm{~h}$ of unpreserved storage, respectively. This subsequent increase rather supports reported trends for post-defecation changes in faecal glucocorticoid metabolite levels in, for example, pigtailed macaques (Macacane mestrina) and the African buffalo (Syncerus caffer) (Wasser et al. 1988; Ganswindt et al. 2012). In addition to microbial activity, aerial-driven chemical processes like redox reactions could also be considered contributing to the respective changes in hormone metabolite concentrations found (Lexen et al. 2008). The distinct fluctuation in steroid metabolite concentrations discovered in spiny mouse faeces over just three hours post-defecation underline once more the importance of controlling for the interval between defecation, sampling, and freezing of the collected material to minimize the potential risk of inadvertent changes in steroid metabolite composition due to active bacterial enzymes present in the faeces (Möstl et al. 1999; Millspaugh \& Washburn 2004).

As in other rodents (New Mexico Department of Health), spiny mice faecal samples vary greatly in size and mass with sometimes very low overall quantities (P.R. de Bruin, pers. obs.). In this regard, Millspaugh \& Washburn (2004) examined the influence of sample mass used for hormone extraction and showed that comparatively small faecal samples $(<0.02 \mathrm{~g})$ result in proportionately higher hormone concentrations, which subsequently biased the findings. Our results partly confirm the described pattern, as faecal material of less than $0.03 \mathrm{~g}$ used for hormone extraction showed greater variability in respective hormone metabolite levels. As a possible explanation for the revealed pattern, it was hypothesized that small sample size may result in a biased representation of hormone metabolite data because of microbial activity resulting in a higher metabolite concentration per gram mass (Millspaugh \& Washburn 2004; Temple \& Gutiérrez 2004). To overcome the problem of insufficient sample mass, which might be an expectable issue for studies involving small animals like mice, material could be pooled to a certain extent (Suedkamp Wells et al. 2003). Visual estimates for the degree of variability in the mass-dependent results reported by Millspaugh \& Washburn (2004) also indicate a proportionally slightly higher variance in faecal glucocorticoid metabolite values when a relatively large faecal mass ( $\geq 125 \mathrm{mg}$ ) was used for hormone extraction. This is again in line with our results, as we also found a slightly higher coefficient of variation for the sample set including masses of $75 \mathrm{mg}$ faeces for extraction. Although the reason for this increase in variability is unknown, a comparatively less-thanideal hormone extraction procedure for faecal samples of larger masses is conceivable.

So far, the length of the oestrous cycle in spiny mice has only been examined in the common and golden spiny mice (Peitz 1981; van Aarde \& Haim 1999) by investigating vaginal smears and plasma progesterone levels. However, the described cycle length of 11-18 days for the two Acomys species (Peitz 1981; van Aarde \& Haim 1999) is comparable to length of the two oestrous cycles (16 and 18 days, respectively) identified in this study. However, compared to other rodent species, including gerbils, the oestrous cycle of the three investigated spiny mouse species is approximately three-times longer in duration (Parkes 1926; Barfield \& Beeman 1968). A possible explanation for this could be a difference in social organization, although respective data for $A$. spinosissimus are lacking (Skinner \& Chimimba 2005). If spiny mice are solitary as already predicted for Acomys russatus (Haim 1991), the comparatively long oestrous cycle could allow potential mates to get used to each other, thereby enhancing the possibility for the male to frequently monitor the female in order to allow copulation to take place within the fertile window. It is also possible that maturation 
of the follicles takes much longer than in other species, resulting in an extended oestrous cycle. Therefore, investigations into the time required for the ovarian follicles to develop into Graafian follicles ready to rupture could aid in the explanation of the comparatively long oestrous cycle observed in this genus. The reason for only identifying two cycles out of a possible 14 may be due to the chosen sampling regime in this study, with samples being collected only every second day. Ideally, faecal samples should be collected continuously over a $>20$ day period in order to precisely determine the luteal activity and subsequently the oestrous cycles for this species. However, an alternative biological explanation for the low number of oestrous cycles identified in this study may be the age of the females involved. Although age could not be determined precisely in our study since females were wild caught, it is conceivable that some of the females were sexually immature or already too old to undergo any ovarian activity. However, because we were able to reveal luteal activity in eight out of the 14 study animals, the explanation of a suboptimal sampling regime seems more realistic.

The common spiny mouse is the only Acomys species for which a gestation period has been described and with approximately 39 days its duration is comparable with some rodent species, but generally longer than for most rodents of equal body size (Peitz 1981; Yom-Tov 1985). In our study FPM levels were elevated by over $200 \%$ in a confirmed pregnant female, which again demonstrated the validity of the enzyme immunoassay used for monitoring reproductive function in southern African spiny mice females. However, samples could only be obtained 12 days prior to parturition, and further research would be necessary in order to examine the applicability of our established method to determine pregnancy during the first two-thirds of gestation. Therefore, future studies should ideally continuously monitor female reproductive activity from the day of copulation in order to reveal detailed longitudinal hormone profiles.

The males exposed to a long photoperiod, simulating the austral summer, had elevated FAM levels compared to the males that were exposed to the short photoperiod, simulating the austral winter, which confirmed the findings of Medger et al. (2012a) regarding an existing seasonal pattern in plasma testosterone concentrations for Acomys spinosissimus males. Based on their findings, Medger et al. (2010) concluded that spiny mice are seasonal breeders with the breeding season coinciding with the summer months when the rainfall is maximal in the Limpopo province of South Africa. The revealed differences in FAM levels in reproductively active and inactive males demonstrate the suitability of the enzyme immunoassay used to determine the reproductive state of males in the wild as has been shown for various other species such as Eurasian lynx (Lynx lynx), African elephants (Loxodonta africana) or moustached tamarins (Saguinus mystax) (Ganswindt et al. 2005; Huck et al. 2005; Göritz et al. 2006).

In conclusion, Acomys spinosissimus is a small rodent, making continuous blood sampling for hormone monitoring impossible, and the small amounts of urine usually produced by the species adds another constraint on using this matrix for monitoring reproductive activity. Faecal samples have been used in various rodent species to monitor male and female reproductive activity (Billitti et al. 1998; Schwarzenberger 2007; Busso \& Ruiz 2011), and our study adds to the list by demonstrating that reproductive function can be monitored in male and female spiny mice by measuring respective faecal hormone metabolites. The established techniques could become invaluable as continuous sampling is now possible on an individual level making long term studies more feasible, simultaneously improving the ethical basis for respective experiments as animals would not necessarily have to be euthanased for sample collection.

\section{ACKNOWLEDGEMENTS}

Collection of animals occurred under permits granted by the Department of Nature Conservation in the Limpopo and Gauteng Provinces, respectively. The project was funded by the SARChI Chair for Mammal Behavioural Ecology and Physiology as well as the National Research Foundation to N.C. Bennett. P.R. de Bruin acknowledges a Masters bursary from the NRF and K. Medger a postdoctoral bursary from the University of Pretoria. We would like to thank Dave Dewsnap from Goro Game Reserve for allowing us to work on the premises, Claire Relton for her assistance during the experimental period, and Stefanie Ganswindt for expert help with laboratory techniques.

\section{REFERENCES}

BARFIELD, M.A. \& BEEMAN, E.A. 1968. The oestrous cycle in the Mongolian gerbil, Meriones unguiculatus. Journal of Reproduction and Fertility 17: 247-251. 
BATES, P.J.J. 1994. The distribution of Acomys (Rodentia: Muridae) in Africa and Asia. Israel Journal of Zoology 40: 199-214.

BERKELEY, E.V., KIRKPATRICK, J.F., SCHAFFER, N.E., BRYANT, W.M. \& THRELFALL, W.R. 1997. Serum and fecal steroid analysis of ovulation, pregnancy, and parturition in the black rhinoceros (Diceros bicornis). Zoo Biology 16: 121-132.

BILLITTI, J.E., LASLEY, B.L. \& WILSON, B.W. 1998. Development and validation of a fecal testosterone biomarker in Mus musculus and Peromyscus maniculatus. Biology of Reproduction 59: 1023-28.

BROWN, J.L., BELLEM, A.C., FOURAKER, M., WILDT, D.E. \& ROTH, T.L. 2001. Comparative analysis of gonadal and adrenal activity in the black and white rhinoceros in North America by noninvasive endocrine monitoring. Zoo Biology 20: 463-486.

BROWN, J.L., SCHMITT, D.L., BELLEM, A., GRAHAM, L.H. \& LEHNHARDT, J. 1999. Hormone secretion in the Asian elephant (Elephas maximus): characterization of ovulatory and anovulatory luteinizing hormone surges. Biology of Reproduction 61: 1294-99.

BUSSO, J.M., PONZIO, M.F., DABBENE, V., DE CUNEO, M.F. \& RUIZ, R.D. 2005. Assessment of urine and fecal testosterone metabolite excretion in Chinchilla lanigera males. Animal Reproduction Science 86: 339-351.

BUSSO, J.M., PONZIO, M.F., DABBENE, V., DE CUNEO, M.F. \& RUIZ, R.D. 2007. Noninvasive monitoring of ovarian endocrine activity in the chinchilla (Chinchilla lanigera). General and Comparative Endocrinology 150: 288-297.

BUSSO, J.M. \& RUIZ, R.D. 2011.Contemporary Aspects of Endocrinology. InTech, Rijeka, Croatia, DOI: 10.5772/17051.2011, pp. 375-396.

CAVIGELLI, S.A., MONFORT, S.L., WHITNEY, T.K., MECHREF, Y.S., NOVOTNY, M. \& McCLINTOCK, M.K. 2005. Frequent serial fecal corticoid measures from rats reflect circadian and ovarian corticosterone rhythms. Journal of Endocrinology 184: 153-163.

FRYNTA, D., NOVÁKOVÁ, M., KUTALOVÁ, H., PALME, R. \& SEDLÁČEK, F. 2009. Apparatus for collection of fecal samples from undisturbed spiny mice (Acomys cahirinus) living in a complex social group. Journal of the American Association for Lab Animals 48: 196-201.

GANSWINDT, A., HEISTERMANN, M., BORRAGAN, S. \& HODGES, J.K. 2002. Assessment of testicular endocrine function in captive African elephants by measurement of urinary and fecal androgens. Zoo Biology 21: 27-36.

GANSWINDT, A., RASMUSSEN, H.B., HEISTERMANN, M. \& HODGES, J.K. 2005. The sexually active states of free-ranging male African elephants (Loxodonta africana): defining musth and non-musth using endocrinology, physical signals, and behavior. Hormones and Behaviour 47: 83-91.

GANSWINDT, A., TORDIFFE, A.S.W., STAM, E., HOWITT, M.J. \& JORI, F. 2012. Determining adrenocortical activity as a measure of stress in African buffalo (Syncerus caffer) based on fecal analysis. African Zoology 47: 261-269.

GÖRITZ, F., NEUBAUER, K., NAIDENKO, S.V., FICKEL, J. \& JEWGENOW, K. 2006. Investigations on repro- ductive physiology in the male Eurasian lynx (Lynx lynx). Theriogenology 66: 1751-54.

GOYMANN, W. 2012. On the use of non-invasive hormone research in uncontrolled, natural environments: the problem with sex, diet, metabolic rate and the individual. Methods in Ecology and Evolution 3: 757-765.

HAIM, A. 1991. Behavior patterns of cold-resistant Golden spiny mouse Acomys russatus. Physiology and Behaviour 50: 641-643.

HODGES, K., BROWN, J. \& HEISTERMANN, M. 2010. Principles and Techniques for Zoo Management. University of Chicago Press, Chicago.

HUCK, M., LÖTTKER, P., HEYMANN, E.W. \& HEISTERMANN, M. 2005. Characterization and social correlates of fecal testosterone and cortisol excretion in wild male Saguinus mystax. International Journal of Primatology 26: 159-179.

KUZNETSOV, V.A., TCHABOVSKY, A.V., KOLOSOVA, I.E. \& MOSHKIN, M.P. 2004. Effect of habitat type and population density on the stress level of midday gerbils (Meriones meridianus Pall.) in free-living populations. Biological Bulletin 6: 628-632.

LAVER, P.N., GANSWINDT, A., GANSWINDT, S.B. \& ALEXANDER, K.A. 2012. Non-invasive monitoring of glucocorticoid metabolites in banded mongooses (Mungos mungo) in response to physiological and biological challenges. General and Comparative Endocrinology 179: 178-183.

LEXEN, E., EL-BAHR, S.M., PALME, R. \& MÖSTLE, E. 2008. Monitoring disturbance in sheep by measuring glucocorticoid metabolites in feces. Wiener tierärtzlichen Monatsschrift 95: 64-71.

LUDWIG, C., WACHTER, B., SILINSKI-MEHR, S., GANSWINDT, A., BERTSCHINGER, H., HOFER, H. \& DEHNHARD, M. 2013. Characterisation and validation of an enzyme-immunoassay for the noninvasive assessment of fecal glucocorticoid metabolites in cheetahs (Acinonyx jubatus). General and Comparative Endocrinology 180: 15-23.

MEDGER, K., CHIMIMBA, C.T. \& BENNETT, N.C. 2010. Seasonal reproduction in the female spiny mouse from South Africa. Journal of Zoology (London) 282: 163-170.

MEDGER, K., CHIMIMBA, C.T. \& BENNETT, N.C. 2012a. Seasonal changes in reproductive development in male spiny mice (Acomys spinosissimus) from South Africa. Mammalian Biology 77: 153-159.

MEDGER, K., CHIMIMBA, C.T. \& BENNETT, N.C.2012b. Reproductive photoresponsiveness in male spiny mice from South Africa. Journal of Zoology (London) 286: 243-249.

MILLSPAUGH, J.J. \& WASHBURN, B.E. 2004. Use of fecal glucocorticoid metabolite measures in conservation biology research: considerations for application and interpretation. General and Comparative Endocrinology 138: 189-199.

MÖSTL, E., MAGGS, J.L., SCHRÖTTER, G., BESENFELDER, U. \& PALME, E. 2002. Measurement of cortisol metabolites in feces of ruminants. Veterinary Research Communications 26: 127-137.

MÖSTL, E., MESSMANN, S., BAGU, E., ROBIA, C. \& PALME, R. 1999. Measurement of glucocorticoid metabolite concentrations in feces of domestic live- 
stock. Journal of Veterinary Medicine Series A 46 : 621-631.

NEW MEXICO DEPARTMENT OF HEALTH. Domestic rats and mice. Online at: http://nmhealth.org (accessed 15 January 2013).

NISHINO, N. \& TOTSUKAWA, K. 1996. Study on the estrous cycle in the Mongolian gerbil (Meriones unguiculatus). Experimental Animals 45: 283-288.

NOVÂKOVÁ, M., PALME, R., KUTALOVÁ, H., JANSKÝ, L. \& FRYNTA, D. 2008. The effects of sex, age and commensal way of life on levels of fecal glucocorticoid metabolites in spiny mice (Acomys cahirinus). Physiology and Behaviour 95: 187-193.

NOWAK, R.M. 1999. Walker's Mammals of the World. Johns Hopkins University Press, Baltimore.

PALME, R., FISCHER, P., SCHILDORFER, H. \& ISMAIL, M.N. 1996. Excretion of infused ${ }^{14} \mathrm{C}$-steroid hormones via feces and urine in domestic livestock. Animal Reproduction Science 43: 43-63.

PALME, R. \& MÖSTL, E.1993. Biotin-streptavidin enzyme immunoassay for the determination of oestrogens and androgens in boar feces. In: Proceedings of the 5th Symposium on the Analysis of Steroids; 1993, Hungary.

PARKES, A.S. 1926. Observations on the oestrous cycle of the albino mouse. Proceedings of the Royal Society of London B Biological Science 100: 151-170.

PEITZ, B. 1981. The oestrous cycle of the spiny mouse (Acomys cahirinus). Journal of Reproduction and Fertility 61: 453-459.

PETTITT, B.A., WHEATON, C.J. \& WATERMAN, J.M. 2007. Effect of storage treatment on fecal steroid hormone concentrations of a rodent, the Cape ground squirrel (Xerus inauris). General and Comparative Endocrinology 150: 1-11.

SCHWARZENBERGER, F. 2007. The many uses of non-invasive fecal steroid monitoring in zoo and wildlife species. International Zoo Yearbook 41: 52-74.

SCHWARZENBERGER, F., TOMÁŠOVÁ, K., HOLEČKOVÁ, D., MATERN, B. \& MÖSTL, E. 1996. Measurement of fecal steroids in the black rhinoceros (Diceros bicornis) using group-specific enzyme immunoassays for 20-oxo-pregnanes. Zoo Biology 15: 159-171.

SCHWARZENBERGER, F., RIETSCHEL, W., VAHALA, J., HOLECKOVA, D., THOMAS, P., MALTZAN, J., BAUMGARTNER, K. \& SCHAFTENAAR, W. 2000. Fecal progesterone, estrogen, and androgen metabolites for noninvasive monitoring of reproductive function in the female Indian rhinoceros, Rhinoceros unicornis. General and Comparative Endocrinology 119: 300-307.
SHANAS, U. \& HAIM, A. 2004. Diet salinity and vasopressin as reproduction modulators in the desertdwelling golden spiny mouse (Acomys russatus). Physiology and Behaviour 81: 645-650.

SHARGAL, E., KRONFELD-SCHOR, N. \& DAYAN, T. 2000. Population biology and spatial relationships of coexisting spiny mice (Acomys) in Israel. Journal of Mammalogy 81: 1046-1052.

SKINNER, J.D. \& CHIMIMBA, C.T. 2005. The Mammals of the Southern African Subregion. Cambridge University Press, Cambridge.

SUEDKAMP WELLS, K.M., WASHBURN, B.E., MILLSPAUGH, J.J., RYAN, M.R. \& HUBBARD, M.W. 2003. Effects of radio-transmitters on fecal glucocorticoid levels in captive dickcissels. The Condor 105: 805-810.

TEMPEL, D.J. \& GUTIÈRREZ, R.T. 2004. Factors related to fecal corticosterone levels in California spotted owls: implications for assessing chronic stress. Conservation Biology 18: 538-547.

TOUMA, C. \& PALME, R. 2005. Measuring fecal glucocorticoid metabolites in mammals and birds: the importance of validation. Annals of the New York Academy of Science 1046: 54-74.

VALADES, G.B., GANSWINDT, A., ANNADALE, H., SCHULMAN, M.L. \& BERTSCHINGER, H.J. 2012. Non-invasive assessment of the reproductive cycle in free-ranging female African elephants (Loxodonta africana) treated with a gonadotropin-releasing hormone $(\mathrm{GnRH})$ vaccine for inducing anoestrus. Journal of Reproductive Biology and Endocrinology 10: 63.

VAN AARDE, R. \& HAIM, A. 1999. The influence of urinary and fecal odors on ovarian function in coexisting Acomys species. Israel Journal of Zoology 45: 261-265.

VERHEYEN, W., HULSELMANS, J., WENDELEN, W., LEIRS, H., CORTI, M., BACKELJAU, T. \& VERHEYEN, E. 2011. Contribution to the systematics and zoogeography of the East-African Acomys spinosissimus Peters 1852 species complex and the description of two new species (Rodentia: Muridae). Zootaxa 3059: 1-35.

WASSER, S.K., RISLER, L. \& STEINER, R.A. 1988. Excreted steroids in primate feces over the menstrual cycle and pregnancy. Biology of Reproduction 39: 862-872.

WUBE, T., HAIM, A. \& FARES, F. 2008. Reproductive response of xeric and mesic populations of the spiny mouse Acomys to photoperiod acclimation. Journal of Arid Environments 72: 40-447.

YOM-TOV, Y. 1985. The reproductive rates of Australian rodents. Oecologia (Berlin) 66: 250-255.

Responsible Editor: A. Monadjem 